Archived version from NCDOCKS Institutional Repository http://libres.uncg.edu/ir/asu/

Cherry, Todd, Steffen Kallbekken, Stephan Kroll and David McEvoy. (2013). Cooperation In and Out of the Market: An Experimental Comparison of Public Good Games and Markets with Externalities. Economics Letters, 120(1): 93-96. Published by Elsevier www.elsevier.com (ISSN: 0165-1765). DOI: 10.1016/j.econlet.2013.03.034

\title{
Cooperation in and out of markets: An experimental comparison of public good games and markets with externalities
}

Todd L. Cherry, Steffen Kallbekken, Stephan Kroll, David M. McEvoy

\begin{abstract}
Experimental studies have compared cooperation across different nonmarket social dilemma settings, but the experimental literature has largely overlooked comparing cooperation across market and nonmarket settings. This paper reports the results from an experiment that compares behavior in theoretically equivalent public good games and market games with externalities. Both positive and negative external effects are considered. Results indicate that people tend to be less cooperative in the marketplace relative to the nonmarket setting, whether the external effect is positive or negative. Most striking is the finding that the combination of a positive external effect in a nonmarket setting (i.e., the standard public good game) stands apart from the other market and nonmarket settings.
\end{abstract}

\section{Keywords}

Cooperation; Public goods; Market externalities; Experiments 


\section{Introduction}

Collective action problems occur when there is an externality-when an agent fails to fully internalize the consequences of its action. Externalities exist in and out of markets, leading to market failures and social dilemmas. An extensive experimental literature has examined a wide range of market and nonmarket collective action problems using various experimental frameworks such as the public good game, common-pool resource game, oligopoly game and markets with negative externalities. A particularly prominent social dilemma in the literature is the public good game, in which each individual of a group faces a cost to generate a benefit that is shared by all, therefore creating a tension between what is best for the individual and what is best for the group. While standard models of self-interest predict people will underprovide the public good, results from the lab and field consistently find that people act more cooperatively and provide more of the public good than theory predicts (Ledyard, 1995 and Chaudhuri, 2011).

Researchers have explored how the cooperation observed in the public good game compares to other variants of social dilemmas. Studies show that people are less cooperative when the public good game is reframed as a theoretically equivalent public bad (Andreoni, 1995 and Sonnemans et al., 1998) and people exhibit similar behavior when the social dilemma is constructed as a common-pool resource game (Sell and Son, 1997 and Apesteguia and Maier-Rigaud, 2006). ${ }^{-1}$ This line of inquiry however has not moved beyond social dilemmas to examine how cooperation in the public good game compares to an equivalent market failure. Given collective action problems occur in both market and nonmarket settings, it is important to both researchers and policymakers to understand the behavioral implications of this distinction. The best way to investigate or mitigate a collective action problem might depend on whether the activity that generates the externality occurs in or out of the marketplace. Previous work that uses experimental markets with negative externalities indicate the distinction matters, reporting very little cooperative behavior in the absence of corrective mechanisms (Plott, 1983). However, without a clean comparison, it is not clear whether this casual observation is due to the negative frame or the market institution or the interaction between them.

This paper provides a clean comparison of cooperative behavior in and out of markets by comparing four theoretically equivalent collective action problems that vary in two dimensions: (a) public good dilemma vs. market with an externality and (b) positive externality vs. negative externality. Thus, we isolate the influence of the institutional frame and the positive/negative frame, as well as potentially important interaction effects. Consistent with previous research, we find that the positive/negative frame matters in both the public good and market settings, but we also find the institutional frame affects cooperation. In particular, we provide support for the conjecture that a marketplace generates more selfishness. Most compelling, however, is the importance of the interaction of the positive/negative and institutional frames. In particular, the combination of a positive externality and a collective institution (i.e., the standard public good game) generates unique levels of cooperative behavior. 


\section{Experimental Design}

We employ a $2 \times 2$ design, with treatment variables externality and institution. The externality can be positive or negative, in the sense that an action explicitly increases or decreases the payoffs of others. The institution is either a nonmarket public good game, in which members of a group make contributions to a public account that generates positive or negative returns to everybody, or a market game, in which buyers purchase a good from an automated seller in a simple posted offer market that provides value to them but also generates additional benefits or costs to other market participants. In each treatment, the payoff for the ith subject that contributes/purchases $x_{i}$ units is:

$$
\pi_{i}=e_{i}-a x_{i}+b x_{i}+c \sum_{k \neq i} x_{k}
$$

where $e_{i}$ is the initial endowment, $a$ is the opportunity cost of each contribution/purchase, $\mathrm{bb}$ is subject i's individual return from each of her contributions/purchases, and cc is the benefit/cost received from each of the contributions/purchases made by the other $\mathrm{k}$ subjects.

In the positive-externality public good game, each member of a group of four ( $k=4 k=4)$ is endowed with 10 tokens $\left(e_{i}=10 e i=10\right)$. She must decide how many of her tokens to contribute to the public account $\left(\mathrm{x}_{\mathrm{i}} \mathrm{xi}\right)$. For each token contributed, the member foregoes one token $(a=1 a=1)$ from her private account in exchange for an individual return of 0.4 tokens from the public account while providing a benefit of 0.4 tokens to the other group members $(b=0.4 ; c=0.4 \mathrm{~b}=0.4 ; \mathrm{c}=0.4)$. Similarly, in the positive-externality market game , each buyer in the market is endowed with 10 tokens $\left(e_{i}=10 e i=10\right)$ and must decide how many units $(0-10)$ of a good to buy $\left(x_{i} x_{i}\right)$. For each purchase, the buyer pays a price of one token $(a=1 a=1)$ from her private account and receives a personal benefit of 0.4 tokens while also providing a benefit of 0.4 tokens to each of the other buyers in the market $(b=0.4 ; c=0.4 \mathrm{~b}=0.4 ; \mathrm{c}=0.4)$. In both positive-externality treatments, since $b<a b<a$ each subject contributes zero tokens to the public account in a noncooperative Nash equilibrium and earns 10 tokens.

In the negative-externality public good game, each member of the group is endowed with 16 tokens $\left(\mathrm{e}_{\mathrm{i}}=16 \mathrm{e}=16\right)$. She must decide how many of her tokens to contribute to the public account $\left(\mathrm{x}_{\mathrm{i}} \mathrm{xi}\right)$. For each token contributed, the member foregoes one token $(a=1 a=1)$ from her private account in exchange for an individual return of 1.6 tokens from the public account while imposing a cost of 0.4 tokens to the other group members $(b=1.6 b=1.6 ; c=-0.4 c=-0.4)$. Similarly, in the negative-externality market game , each buyer in the market is endowed with 16 tokens $\left(\mathrm{e}_{\mathrm{i}}=16 \mathrm{e} i=16\right)$ and must decide how many units $(0-10)$ of a good to buy $\left(x_{i} x i\right)$. For each purchase, the buyer pays a price of one token $(a=1 a=1)$ from her private account and receives a personal benefit of 1.6 tokens while also imposing a cost of 0.4 tokens to each of the other buyers in the market ( $b=1.6 ; c=-0.4 \mathrm{~b}=1.6 ; \mathrm{c}=-0.4)$. In both negative-externality treatments, since $\mathrm{b}>\mathrm{ab}>\mathrm{a}$ 
each player will contribute/purchase 10 units and earn 10 tokens in a non-cooperative Nash equilibrium.

Two items are worth noting. First, the four games are theoretically equivalent in the sense that pecuniary self-interested players are expected to earn identical payoffs in equilibrium, and symmetric off-equilibrium behavior yields identical payoffs as well. Second, the four games are operationally identical with differences arising in the framing of roles (member vs. buyer), setting (group vs. market), and actions (contributing vs. purchasing).

The experiments were conducted at Appalachian State University using software specifically designed for this research. For each treatment, players were placed in groups of four that were randomly reshuffled at the beginning of each of 20 periods. For each treatment we have 400 individual observations and 100 group-level observations. One token converted to 0.50 USD and subjects were paid earnings from two randomly chosen periods. Average earnings were $\$ 16$.

\section{Results}

Cooperative behavior is defined as the number of tokens allocated to the cooperative outcome - either through purchases in the market setting or voluntary contributions in the public good setting. Fig. 1 illustrates the mean cooperative behavior over time for all four treatments.

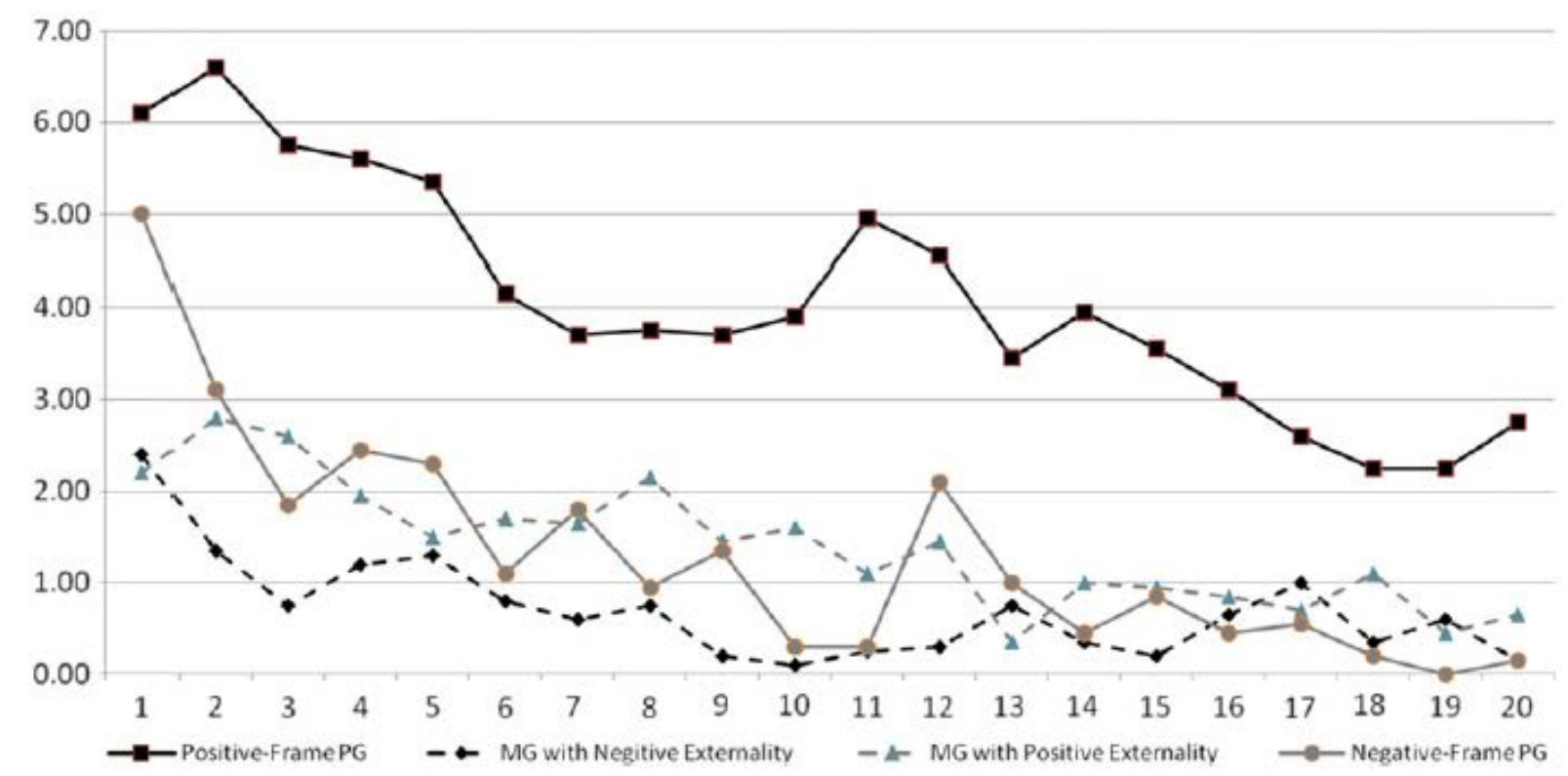

Fig. 1. Average cooperative behavior by treatment over periods.

The data indicate the type of externality (positive vs. negative) significantly influences the level of cooperative behavior in both the public good and market game. Comparing the positive and negative externality in the public good game, cooperative behavior is 
significantly greater in the positive case -41.0 vs. $13.1 \%(p=0.000 p=0.000) . \frac{3}{-}$ This corresponds with previous findings (Andreoni, 1995). We find a much smaller, but still significant, effect in the market game with mean cooperation levels being $14.0 \%$ in the positive-externality case and $7.0 \%$ in the negative-externality case $(p=0.000 p=0.000)$.

Results indicate that the institution also influences cooperative behavior. When the externality is positive, we observe a striking difference in cooperation across the public good and market settings. Specifically, the mean cooperation level is $41.0 \%$ in the positive-externality public good game while only being $14.0 \%$ in the positive-externality market game $(p=0.000 p=0.000)$. A similar result emerges when the externality is negative. Mean cooperation is higher in the negative-externality public good game than the negative-externality market game-13.1 vs. $7.0 \%(p=0.000 p=0.000)$.

The most striking result is the extent that the positive-externality public good treatment stands apart from the other three treatments. Noting that cooperative behavior in this standard public good treatment is very much in line with the large public good literature (see Chaudhuri, 2011), we find this combination of a positive externality and a nonmarket public good setting creates a unique setting for cooperative behavior. This finding is particularly evident in the final periods, when the positive-externality publicgood treatment is significantly different from the other three statistically equivalent treatments.

We confirm our unconditional results with a regression analysis that takes advantage of the panel nature of our data. We estimate the treatment effects on the level of cooperative behavior (in tokens) with a linear panel model that controls for periodspecific fixed-effects and yields robust standard errors with clustering at the individual level. Table 1 reports the results from three models. Model 1 provides the estimates from the pooled data (all 20 periods), and Models 2 and 3 give estimates from data stratified by the first and last 10 periods.

Table 1 Linear regression models on cooperative behavior by treatment

\begin{tabular}{lccc}
\hline & Pooled & Periods 1-10 & Periods 11-10 \\
\hline Constant & $6.144^{* * *}$ & $6.339^{* * *}$ & $2.849^{* * *}$ \\
& $(0.667)$ & $(0.687)$ & $(0.653)$ \\
PG-negative externality & $-2.788^{* * *}$ & $-2.84^{* * *}$ & $-2.735^{* * *}$ \\
& $(0.628)$ & $(0.700)$ & $(0.669)$ \\
MKT-negative externality & $-3.398^{* * *}$ & $-3.915^{* * *}$ & $-2.880^{* * *}$ \\
& $(0.625)$ & $(0.673)$ & $(0.686)$ \\
MKT-positive externality & $-2.690^{* * *}$ & $-2.900^{* * *}$ & $-2.480^{* * *}$ \\
& $(0.681)$ & $(0.755)$ & $(0.702)$ \\
\hline$F$ & $6.15^{* * *}$ & $7.55^{* * *}$ & $3.43^{* * *}$ \\
$R^{2}$ & 0.252 & 0.243 & 0.211 \\
$N$ & 1600 & 800 & 800 \\
\hline
\end{tabular}

Notes: Models control for period-specific fixed-effects and standard errors are robust and clustered at the individual level. ${ }^{*},{ }^{* *}$ and ${ }^{* * *}$ indicate significance at the 10,5 and 1 percent level, respectively. 
The conditional analysis confirms our initial impressions and highlights three key findings. First, estimates show that the type of externality (positive vs. negative) matters in both the public good and market games. Cooperation is higher in the case of a positive externality in the public good game $(p=0.000 p=0.000)$ and market game $(p=0.052 p=0.052)$. Second, results indicate the institution also affects cooperative behavior. Regardless of the externality frame, cooperative behavior is significantly lower in the market game than in the public good game (positive: $p=0.000 p=0.000$; negative: $p=0.016 p=0.016$ ). Third, the interaction of the externality and institution is important, particularly over time. Estimates from Models 2 and 3 show that, while the distinctions of externalities and institutions matter initially, the effects disappear over time in some cases. Specifically, pair-wise coefficient tests in the last 10 periods confirm that the market game becomes unaffected by the type of externality over time $(p=0.244 p=0.244)$, and the negative externality becomes unaffected by the institution over time $(p=0.586 p=0.586)$. The resulting outcome is that the positive-externality public good treatment generates much greater cooperative behavior than the other three treatments. Indeed, in the final 10 periods, only the standard public good treatment significantly differs from the other three treatments $(p=0.000 p=0.000)$.

\section{Conclusion}

Experimental studies have compared cooperation across various social dilemma settings, but the literature is silent on comparing nonmarket social dilemmas to equivalent market failures. This paper offers initial insights on this issue by comparing cooperation levels observed in equivalent public good games and laboratory markets with externalities. People tend to be less cooperative in the marketplace relative to the nonmarket setting, though this result fades over time. Most striking is that the standard public good game stands apart from the other settings. Thus, while the type of externality and institution matters, their interaction appears to matter most. 


\section{References}

Andreoni, James, 1995. Warm-glow versus cold-prickle: the effects of positive and negative framing on cooperation in experiments. Quarterly Journal of Economics 110 (1), 1-21.

Ansink, Erik, Bouma, Jetske, 2013. Framed field experiments with heterogeneous frame connotation. MPRA Paper No. 43975.

Apesteguia, Jose, Maier-Rigaud, Frank, 2006. The role of rivalry: public goods versus common-pool resources. Journal of Conflict Resolution 50 (5), 646-663.

Chaudhuri, Ananish, 2011. Sustaining cooperation in laboratory public goods experiments: a selective survey of the literature. Experimental Economics 14 (1), 47-83.

Davis, Douglas D., Holt, Charles A., 1994. Market power and mergers in laboratory markets with posted prices. The RAND Journal of Economics 25 (3), 467-487.

Ellingsen, Tore, Johannesson, Magnus, Mollerstrom, Johanna, Munkhammar, Sara, 2012. Social framing effects: preferences or beliefs? Games and Economic Behavior 76, 117-130.

Ledyard, John, 1995. Public good: a survey of experimental results. In: Kagel, J., Roth, A. (Eds.), The Handbook of Experimental Economics. Princeton University Press, Princeton, New Jersey, pp. 111-194.

Messer, Kent D., Suter, Jordan F., Yan, Jubo, Context effects in a negatively framed social dilemma experiment. Environmental and Resource Economics (forthcoming).

Plott, Charles R., 1983. Externalities and corrective policies in experimental markets. The Economic Journal 93 (1), 106-127.

Plott, Charles R., Smith, Vernon L., 1978. An experimental examination of two exchange institutions. The Review of Economic Studies 45 (1), 133-153.

Sell, Jane, Son, Yeongi, 1997. Comparing public goods with common pool resources: three experiments. Social Psychology Quarterly 60 (2), 118-137.

Sonnemans, Joep, Schram, Arthur, Offerman, Theo, 1998. Public good provision and public bad prevention. Journal of Economic Behavior and Organization 34 (1), 143-161. 